\title{
Exploring the Use of Information and Communication Technology in Advancing the Goals of Education for All among Adults in Nigeria
}

\author{
ORIM, BRIAN AGEM \\ brianorim@yahoo.com \\ Department Of Primary Education Unit, \\ Local Government Universal Basic Education, \\ Obudu Local Government Area, \\ Cross River State, \\ Nigeria
}

\begin{abstract}
Education is a right. Like the right to have proper food or a roof over your head. It is not only a right but a passport to human development. The ideas of Education for all is to expand early childhood care and education, provide free and compulsory primary education for all, promote learning and life skills for young people and adults, increase adult literacy, achieve gender parity and improve the quality of education. The paper sets to explore the use of information and communication technology in advancing the goals of education for all (stated above) among adults in Nigeria. Areas such as information and communication technology and distance learning, education for all; the place of adult education and information and communication technology and the attainment of education for all initiative will be examined.
\end{abstract}

Keywords: Education for All, Distance Learning, ICT, Adult Literacy, Adult Education, and Digital gap.

\section{Introduction}

Information and Communication Technology (ICT) refers to technologies that provide access to information through telecommunications. It is similar to Information Technologies (IT), but focuses primarily on communication technologies. This include the internet, wireless networks, cell phones and other communication mediums.

In the past few decades, information and communication technology have provided society with a vast array of new communication capabilities. For example, people communicate in real-time with others in different countries using technologies such as instant messaging, voice over IP (VO IP), and video-conferencing. Social networking website like Facebook allows users from all over the world to remain in contact and communicate on a regular basis.

Modern information and communication technologies have created a "global village" in which people can communicate with others across the world as if they were living next door. For this reason, ICT is often studied in the context of how modern communication technologies affect society.

Also, information and communication technology is an umbrella term that includes any communication device or application, encompassing: radio, television, cellular phones, computer and network hardware and software, satellite systems and so on, as well as the various services and applications associated with them, such as ICTs in education, health care, or libraries.

According to the European Commission, the importance of ICT lies in the technology itself than in its ability to create greater access to information and communication in underserved populations. Many countries around the world have established organizations for the promotion of ICTs, because it is feared that unless less technologically advanced areas have a chance to catch up, the increasing technological advances in developed nations will only serve to exacerbate the already-existing economic gap between technological "have" and "have not" areas. Internationally, the united nations actively promotes ICTs for Development (ICTAD) as a means of bringing the digital gap.

In developing country like Nigeria where the 'digital gap' is more the rule than the exception, delivering instruction through the distance mode presents a significant challenge to education. In a nation where the concern of most people is 
ISSN 2411-9563 (Print) ISSN 2312-8429 (Online)
European Journal of Social Sciences Education and Research
September-December 2014

Volume 1, Issue 2

meeting their basic needs for food, clothing and shelter, access to information and communication technologies (ICT), especially the most modern ones, is very low on their list of priorities and oftentimes, not considered a priority at all.

Nonetheless, ICT has had a major impact on open and distance learning (ODL) in Nigeria. More than the availability of these technologies, issues such as geographical location, lack of knowledge and skills to use ICT, and financial constraints, are major considerations in deciding what ICT to use and in what combination. Indeed, the use of a particular ICT must not only seek to address certain pedagogical concerns, it must aim at bridging the digital divide and democratize access to quality education. Experience has shown that when a decision has been made to use a technology in ODL, this decision influences not only the teaching and learning environment, but leads to the development of new culture, concepts and understanding. Put simply, the introduction of ICT can alter or raise experience among users and institutions alike.

Education is a right, not only a right but a passport to human development. It open doors and expands opportunities and freedoms. It contributes to fostering peace, democracy and economic growth as well as improving health and reducing poverty. The ultimate aim of Education for All (EFA) is sustainable development.

\section{Information and Communication Technology and Distance Learning:}

Distance education, distance learning or D-learning is a mode of delivering education and instruction, often on an individual basis, to students who are not physically present in a traditional setting such as a classroom. Distance learning provides "access to learning when the source of information and the learners are separated by time and distance, or both". Distance education courses that require a physical on-site presence for any reason (including taking examinations) have been referred to as hybrid or blended courses of study. Massive open online courses (MOOCs), aimed at large-scale interactive participation and open access via the web or other network technologies, are recent development in distance education.

ICTs use to support distance learning can be classified into two categories, the first being hardware and second being software. The hardware currently in use are roughly the same among all Nigerian institutions; radio, television, telephone (land, mobile, fax, voice over, internet Protocol or VO IP), and computers. ICTs have now converged thanks to recent advances and enhancement made to the infrastructure such as laying of fiber optic cables and satellite and microwave transmission facilities. What differ, however, are the levels of use and applications of specific hardware technologies and purpose driving their use.

Given the proliferation of cellular mobile telephone use across all sectors of the Nigerian society, it is becoming increasingly evident that this highly mobile form of technology and its infrastructure can be leveraged to deliver flexible educational opportunities to more and more Nigerian. In other words, simple low-cost cellular mobile telephones are now helping Nigerians bridge the once formidable digital gap.

There are wide variations in ICT used in open and distance learning (ODL) institutions around the world. Further, specific applications and combinations of these applications are very much shaped by the context of their target user populations. In Nigeria, the various ways and means in which ICTs are used include delivery instructional content.

Depending on learner needs and appropriate pedagogy, instructional contents are packaged in various formats using different media. As mentioned, the development of open distance learning mentioned, the development of open distance learning (ODL) in Nigeria witness instructional packages delivered in prints, audiotapes, videotapes, and CD-ROM. In recent years, going online has made Web-enhanced teaching and learning possible, using rich online resources to supplement and update instructional materials vis-à-vis attaining the goals of education for all.

Other academic institutions, however have explored the potentials of mobile devices such as cell phones, Ipad etc, for educational purposes. These initiatives tend to be geared towards the augmenting that traditional face-to-face instructional offerings. Such is the case the text 2 teach project of the Department of Education in Philippines which integrates digital satellite broadcast and mobile phone communications to deliver science materials via video broadcast directly from the classroom (Domigo, 2006). The Advance Science and Technology Institutes of the Department of Science and Technology, Philippines, has also been experimenting with Bluetooth, technology to connect various personal devices in close proximity to each other. Such research and development initiatives are now leading to new and potential avenues of further research, which educators must explore in their guest to provide learners with more innovative and practical method of delivering education at a distance. 


\section{Distance Learning and Education for All Initiative:}

Education for All is a global movement lead by Unite Nation Education, Scientific and Cultural Organization (UNESCO) aiming to meet the needs of all children, youths and adults by 2015 .

UNESCO has been mandated to lead the movement and coordinates the international efforts to reach Education for All. Governments, development agencies, civil society, non-governmental organizations and the media are some of the partners working towards reaching these goals.

Distance learning can expand access to education and training for both general populace and businesses since its flexible scheduling structure lessons the effects of the many times-constraints imposed by personal responsibilities and commitments. Devolving some activities off-site alleviate institutional capacity constraints arising from the traditional demand on institutional building and infrastructure. Furthermore, there is the potential for increased access to more experts in the field and to other students from divers' geographical, social, cultural, economic and experiential background. As the population at large becomes more involved in lifelong learning beyond the normal schooling age, institutions can benefit financially, and adult learning business courses may be particularly lucrative. Distance education programmes can act as a catalyst for institutional innovation and at least as effective as face-to-face learning programmes, especially if the instructor is knowledgeable and skilled.

Distance education can also provide a broader method of communication within the realm of education. With the many tools and programmes that technological advancements have to offer, communication appears to increase in distance education amongst students and their professors, as well as students and their classmates. The distance educational increase in communication, particularly communication amongst students and their classmates is an improvement that has been made to provide distance education students with as many opportunities as possible as they would receive in inperson education. The improvement being made in distance education is growing in tandem with the constant technological advancements. Present day online communications allows students to associate with accredited schools and programmes throughout the world that are out of reach for in-person learning. By having the opportunity to be involved in global institutions via distance education, a diverse array of thought is presented to students through communication with their classmates. This is beneficial because students have the opportunity to "combine new opinions with their own, and develop a solid foundation for learning".

The high cost of education affects students in the higher education to which distance education may be an alternative in order to provide some relief. Distance education has been a more cost effective form of learning, and can sometimes save students a significant amount of money as opposed to traditional education. Distance education may be able to help to save students a considerable amount financially by removing the cost of transportation. In addition, distance education may be able to save student from the economic burden of high priced course textbooks. Many textbooks are now available as electronic textbooks, known as e-textbooks, which can offer digital textbook for a reduced price in comparison to traditional textbooks. Also, the increasing improvement in technology have resulted in many school libraries having a partnership with digital publishers that offers course material for free, which can help students significantly with educational costs.

Within the class, students are able to learn in ways that traditional classrooms would not be able to provide. It is able to promote good learning experiences and therefore, allow students to obtain higher satisfaction with their online learning. For example, students can review their lessons more than once according to their need. Students can then manipulate the course work to fit their learning by focusing more on their weaker topics while breezing through concepts that they already have or can easily grasp. When course design and the learning environment are at their optimal conditions, distance learning education can lead students to higher satisfaction with their learning experiences. Studied have shown that high satisfaction correlates to increased learning. Students who are enrolled in distances education with high satisfaction in their online coursework are then motivated intrinsically to learn, which often means that their performances in class will improve. For those in healthcare or mental health distance learning programs, online-based interactions have the potential to foster deeper reflections and discussion of client issues as well as quicker response to client issues, since supervision happens on a regular basis is not limited to a weekly supervision meeting. This also may contribute to the students feeling a greater sense of support, since they have ongoing and regular access to their instructors and other students.

Distance Learning may enable students who are unable to attend a traditional school setting, due to disability or illness such as decreased mobility and immune system suppression, to get a good education. Distance education may provide equal access regardless of socioeconomic status or income, area of residence, gender, race, age or cost per student. Applying universal design strategies to distance learning courses as they are being developed (rather than instituting 
accommodation for specific students on an as-need basis) can increase the accessibility of such courses to students with a range of abilities, disabilities, learning styles and native languages.

Distance Learning may also offer a final opportunity for adolescence that are no longer permitted in the General Education population due to behavior disorders. Instead of these students having no other academic opportunities, they may continue their education from their homes and earn their school certificates, diplomas etc. offering them another chance to be an integral part of the society.

\section{Education for All, the place of Adult Education.}

Through adult education, education reaches the grassroots and the less privilege benefits. People who have an opportunity to continually learn and develop their skill and capacities will in turn; make our economy grow and develop, ensure that their children develop love of learning and take full advantage of education vis-à-vis the attainment of the goals of education for all. Adult educations make it possible for the participant to actively participate in their own communities and civil society. It makes it possible for beneficiaries of the education programmes to support and respect people with different cultural beliefs and abilities, respect and protect the environment for future generations, nurture creativity and imagination and live healthy and fulfilled lives. Therefore, to achieve the goals of education for all in 2015 adult education is highly indispensable. So, using adult education as a tool, make sense for individuals, families, communities, and our country as a whole.

In the past, it was taken for granted that the older you are, the more wisdom you have collected through life experiences and education over the years. These days, however many adults suffer from illiteracy and a lack of knowledge due to the minimal amount of emphasis that was place on education in the past. This has made it necessary for many individual not only in the African continent, but across the world to require some form of adult education so that they can improve their level of education.

The most important factor that affect the need for adult education is that the adult in the society are the people who are responsible for educating the next generation. It may be all good and well to say that this falls to the education and schooling system in a country, but this is not always the case. Education is now considered a basic human right, there are many cases where this is just not possible. A parent who has received adult education is the best educator for his or her children and can plant the necessary seeds within their children to make them hunger for knowledge and development.

Education is for all. Therefore, giving the benefit of education to just one person in a rural community has been shown to have enormous effect on the population group of that community.

ICT and the attainment of Education for All Initiatives:

Information and Communication Technology (ICT) should be harnessed to support EFA goals at an affordable cost. These technologies have great potential for knowledge dissemination, effective learning and development of more efficient education services. These potentials will not be realized unless the new technologies serve rather than drive the implementation of education strategies. To be effective especially in developing countries, ICTs should be combined with more traditional technologies such as books and radios, and be more extensively applied to the training of teachers.

There is need to tap the potentials of ICT to enhance data collection and analysis from central ministries through subnational levels to the school; to improve access to education by remote and disadvantaged communities; to support initial and continuing professional development of teachers and provide opportunities to communicate across classrooms and cultures.

News media should also be engaged to create and strengthen partnership with education systems, through the promotion of local newspapers, informed coverage of education issues and continuing education programmes via public service broadcasting.

The best general outline to date of how ICTs can be utilized to help realize education for all and other education related MDGs can be found in UNESCO's applying New Technologies and cost-Effective Delivery System in Basic Education. i.e.

There is no alternative to primary education/schools technology based alternatives have not thrived.

Although computers have been used in primary schools, but in a modest way, sometimes mainly for games. Their more significant use is at levels above that of basic education. 
Radio, not limited to interactive radio instruction, can enrich basic education and do so at costs much more modest than those of television or computers.

The scale of the demand for junior secondary education and the increased capacity and maturity of students who have completed primary schooling suggested that there may be an important role for the application of technologies to raise quality and widen access at this level.

The record of using mass media for public, adult and non-formal education in areas such as health, citizenship, family planning and agriculture is patchy, but the technologies available are widely understood and the social and educational needs so great that there is a case for continuing investment and activity hereby government and non-governmental organizations alike.

The use of communication technologies intermediaries, teachers and extension agents can have a multiplier effect and is likely to have cost advantages over conventional ways of supporting and updating them. They have the potentials to reduce the isolation of remote, rural teachers and so raise the quality of their work.

If the development of new technologies is not to widen gap between north and south or between the information-rich and the information-poor, national policies are necessary that will explore ways of making cost-effective use for them in vocational education and training and possibly at the higher levels of formal education.

There are models for out-of-school equivalence at this level, and the potential for developing and making available teaching materials that can be used both in school and out of school.

\section{Recommendations}

Resources and materials that enhance effective and efficient use of information and communication technology (ICT) should be provided for academics teachers, students and practioners alike.

Information on all aspect of internet safety and responsible use should be provided to avoid negative usage.

Government and other relevant agencies should establish and interactive environment in which technology (ICT) is used to advance the goals of education for all.

\section{Conclusion}

The paper seeks to explore the use of information and communication technology in attaining the goals of education for all. Information and communication technology and distance learning, distance learning and education for all initiative, education for all: the place of adult education and the potential of ICT in the attainment of the goals of education for all initiative were the areas considered during the course of research of the paper vis-à-vis the advancement of the goals of education for all (EFA).

\section{References}

[1] "Benefits of Online Education" Wordwidelearn.com . Retrieved 13th June, 2014

[2] Bryne, T.C. (1989). Athabasca University.

[3] The Evolution of Distance Education.

[4] Calgary, Alberta; University of Calgary

[5] Press.

[6] Daniel, Sir. John. S. (1998). Mega Universities

[7] and Knowledge Media Technology Strategies for Higher Education. Routledge. Retrieved 12th June 2014.

[8] Educational Benefits of Online Learning. Calpoly.edu.1998. Retrieved 12th June, 2014.

[9] Honey Man, M. Miller, G. (1993). 
[10] "Agriculture Distance Education: A valid Alternative for Higher Education". Proceeding of the 20th Annual National Agricultural Education Research Meeting.

[11] Joseph K. Keh, (1996) pursuit of knowledge

[12] under Difficulties. From self-improvement to Adult Education in America; eduwiki.org. Retrieved 12th June 2014.

[13] "Key Facts" University of London External Programme Website. Iondonexternal.ac.uk.

[14] 15th July 2009. Retrieved 13th June 2014.

[15] Lederman, Doug, (2013). "Growth for Online

[16] Learning". insideHigherEd. Retrieved 12th June, 2014.

[17] Moore, Michael G., Greg Kearsly (2005).

[18] Distance Education a System View (2nd Ed).

[19] "University of London External Programme website" Iondonexternal.ac.uk

[20] 15th July, 2009. Retrived 22nd June, 2014.

[21] Joseph K. Keh, (1998). Pursuit of Knowledge

[22] Under Difficulties:

[23] From Self-improvement to Adult Education in America; eduwiki.org.

[24] 12th June, 2014. 